\title{
Mergers and Acquisitions of ESG Firms: Towards a New Financial Infrastructure?
}

Working Paper, Andreas Dimmelmeier

\section{Introduction}

Private financial institutions, policymakers and regulators have increasingly become interested in "sustainable" finance. Record inflows to funds that invest according to Environmental, Social and Governance (ESG) criteria, the prominent place sustainable finance takes in the EU's recent recovery and the continuing efforts of the now 66 members strong central banking Network for Greening the Financial System (NGFS) illustrate this development.

Yet the meaning of ESG criteria let alone sustainable finance remains ambiguous due to multiple definitions and deliberate greenwashing. Of central importance in defining how sustainability is conceived are measuring standards and conventions as well as the actors that employ them. Whereas standards and conventions like the Global Reporting Initiative (GRI), the Sustainability Accounting Standards Board (SASB) or the FSB Taskforce on Climate-related financial disclosures (FSB TCFD) have been scrutinized by researchers from International Political Economy and related fields (e.g. Thistlethwaite 2015; Christophers 2017), comparatively less attention has been given to the actors that collect and process the data which is needed for the implementation of these standards.

Yet the implementation of forthcoming regulation on sustainable finance will most likely involve actors that source, assess and certify ESG data. This can already be seen in the discussions about the implementation of the EU's sustainable finance taxonomy, where financial institutions have suggested to link it with already existing ESG assessment frameworks (cf. adelphi 2020: 8; PRI 2020: 17). Consequently, ESG firms might in the future be accorded a function where they provide some of the infrastructure of finance in and thus act in a similar way to actors like Credit Rating Agencies.

Hence, there is value in mapping the actors that assess ESG credentials and their relations. Knowing the histories and the evolution of this part of emerging financial infrastructure can also lead to more detailed empirical insights concerning whether the actors in question contribute to greenwashing and the financializaton of nature or not. 


\section{The Consolidation of ESG Data Providers as the Constitution of an Infrastructure}

The proliferation of organisations and reporting frameworks for ESG and/or Corporate Social Responsibility (CSR) data has long been criticized from multiple sides. Whereas people from the financial industry that are dismissive of ESG matters take the lack of correlations between different data providers (e.g. IMF 2019; The Economist 2019) as a proof for the irrelevance of non-financial data, critical observers from outside the financial system contend that such incommensurable frameworks are in the interest of the industry as they enable greenwashing and ESG data shopping, i.e. selecting the methodology that makes an existing portfolio look most sustainable.

To counter the complexity of the ESG space that has been decried as an "alphabet soup" of acronyms, various initiatives for standardization and aggregation have been proposed. The by now defunct (at least judging from the link which now leads to a household product retailer) Global Initiative for Sustainability Ratings (GISR) set itself the task to make the over 100 rating methodologies converge through best practices in order to make ESG information more relevant and prevent questionnaire fatigue from corporates. ${ }^{1}$ More recently and still ongoing, the big four accountancy firms and the World Economic Forum have embarked on a similar quest (Nauman and Temple-West 2020).

Yet what a focus on such initiatives (and their failures) is missing is that there is already an ongoing consolidation in the ESG field that has little to do with convergence to scientific criteria and best practices and a lot with the more profane issue of increasing market shares through mergers and acquisitions. The empirical part below will explore this issue further by mapping the buying activity among ESG firms and the increasing intrusion of mainstream providers of financial services into this field. If the supply of ESG data and the assessment of the portfolios of financial institutions in these terms becomes increasingly concentrated among a "Big N" number of firms, it might make sense to understand these actors and their services through the language of infrastructures and pay attention to the power that the hard-wiring of technical operations into financial practices and regulations confers to the actors carrying out these functions (cf. Bernards and Campbell Verduyn 2019; Braun 2018; Petry et al. 2019 on infrastructures).

\footnotetext{
${ }^{1}$ https://web.archive.org/web/20180224053858/http://ratesustainability.org/about/why-gisr/
} 


\section{The Need for an Aggregated Dataset}

Academics (Avetisyan and Hockerts 2017; Escrig-Olmedo et al. 2019), industry reports (Novethic 2013; SustainAbility 2020) and specialized newspapers (Thomson 2019) have for a long-time paid attention to the consolidation dynamics in the market for ESG firms. Nevertheless, to my best knowledge there is to date not a comprehensive dataset that records the dynamics between these firms. Industry and newspaper sources often do not specify the criteria for inclusion in their assessments of mergers and acquisitions. Academic studies, on the other hand, have been often confined to country case studies (Avetisyan and Hockerts 2017) or have employed theoretical sampling methods focusing on large (Chatterji et al. 2016) or ideal-type (Eccles and Stoehle 2018) ESG firms.

In addition, academic as well as practitioner research sometimes explore multiple relations between firms. For example, the linkages among indices and methodologies - described in one industry report with the phrase "Ratings beget ratings" (SustainAbility 2010: 13) - as well as industry collaborations are often depicted alongside mergers and acquisitions. Finally, some of the existing data collections lump together various types of actors and metrics. The Rate the Raters initiative, for instance, includes ESG firms (e.g. Ecovadis), indices (e.g. Ethibel Sustainable Indices) and awards (e.g. Vaccine Industry Excellence Awards) in its sample of ESG ratings (SustainAbility 2010: 19).

While some of the above mentioned issues like determining who is an ESG company are notoriously difficult to define, I contend that for a larger dataset it makes sense to simplify the relation and the definition of the unit of analysis. As such, below I only explore ESG firms and those that become ESG firms by acquiring an already existing one.

\section{Data}

\begin{tabular}{|l|l|l|}
\hline Paper & Type & Number of ESG firms studied \\
\hline Escrig-Olmedo et al. 2019 & Academic paper & 10 \\
\hline Eccles and Stoehle 2018 & Academic paper & 4 \\
\hline Chaterjee et al. 2016 & Academic paper & 6 \\
\hline Avetisiyan and Ferrery 2013 & Acaemic paper & 16 \\
\hline Brown Flynn 2016 & Industry report & 22 \\
\hline SustainAbility 2020 & Industry report & 31 \\
\hline Novethic 2013 & Industry report & 41 \\
\hline Avetisyan and Hockerts 2017 & Academic paper & 12 \\
\hline
\end{tabular}


I consulted the in part already above-introduced literature from academia, industry and the specialized media to aggregate the ESG firms that have been explored. Table 1 displays the papers I consulted and how many ESG firms were studied in these texts.

Aggregating the data resulted in a consolidated dataset of 88 ESG firms. Excluding those actors that are not ESG firms but e.g. purely financial data providers that were acquired by a firm that also acquired an ESG firm as well as actors on whom no information could be found left 77 actors in the dataset.

To record the attributes of these actors and obtain data about mergers and acquisitions among them I consulted the papers in table 1 . In addition, I checked company websites, Wikipedia entries and the specialized press (e.g. Financial Times, Responsible Investor, Bloomberg).

\section{Results}

Below I first depict the geographical location of the ESG firms in the dataset as well as the year of their incorporation. Afterwards, I turn to the main preoccupation of this paper by displaying mergers and acquisitions in a network graph and in a timeline.

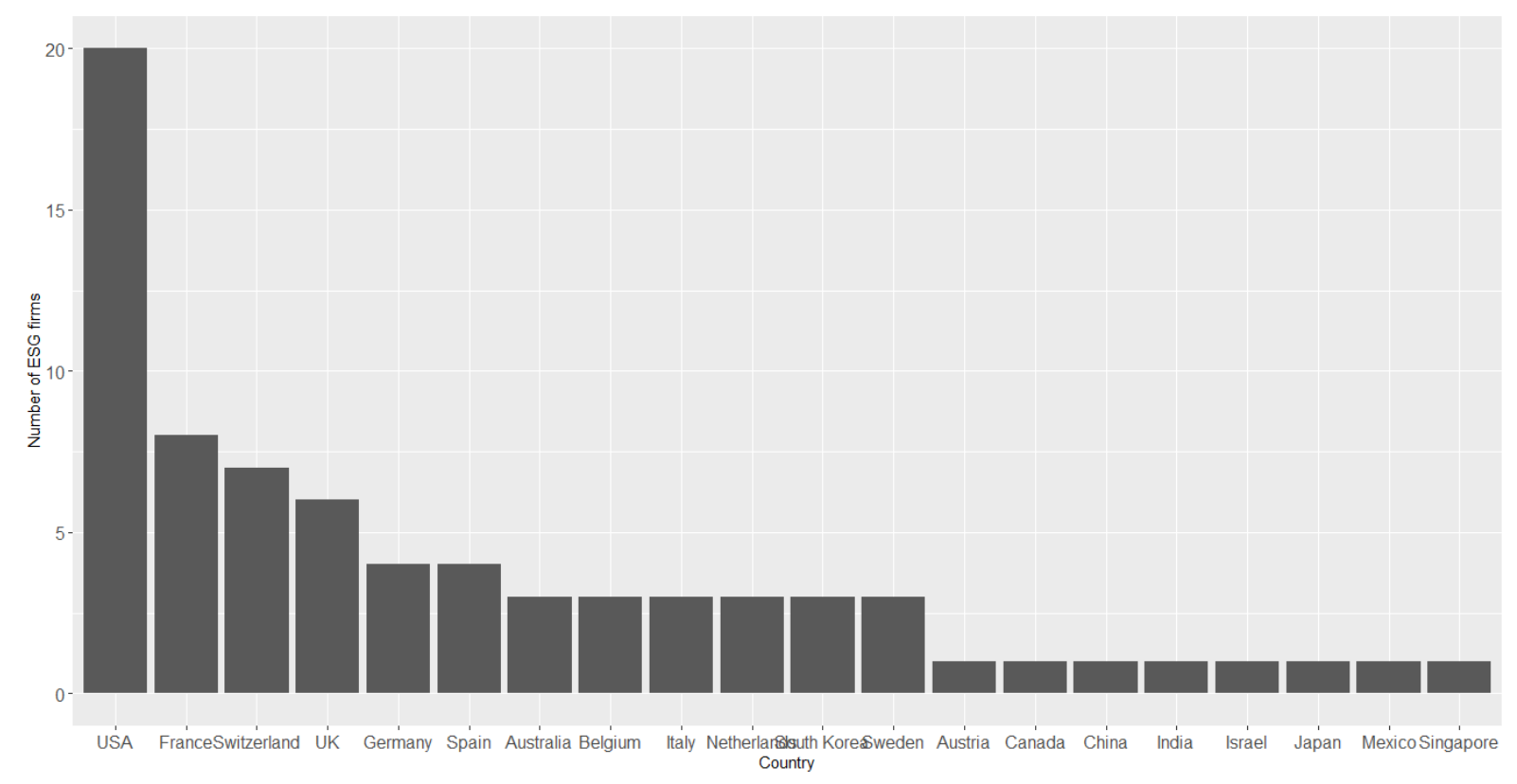

Figure 1: Number of ESG firms by Country 


\section{ESG firms: Geographical Distribution}

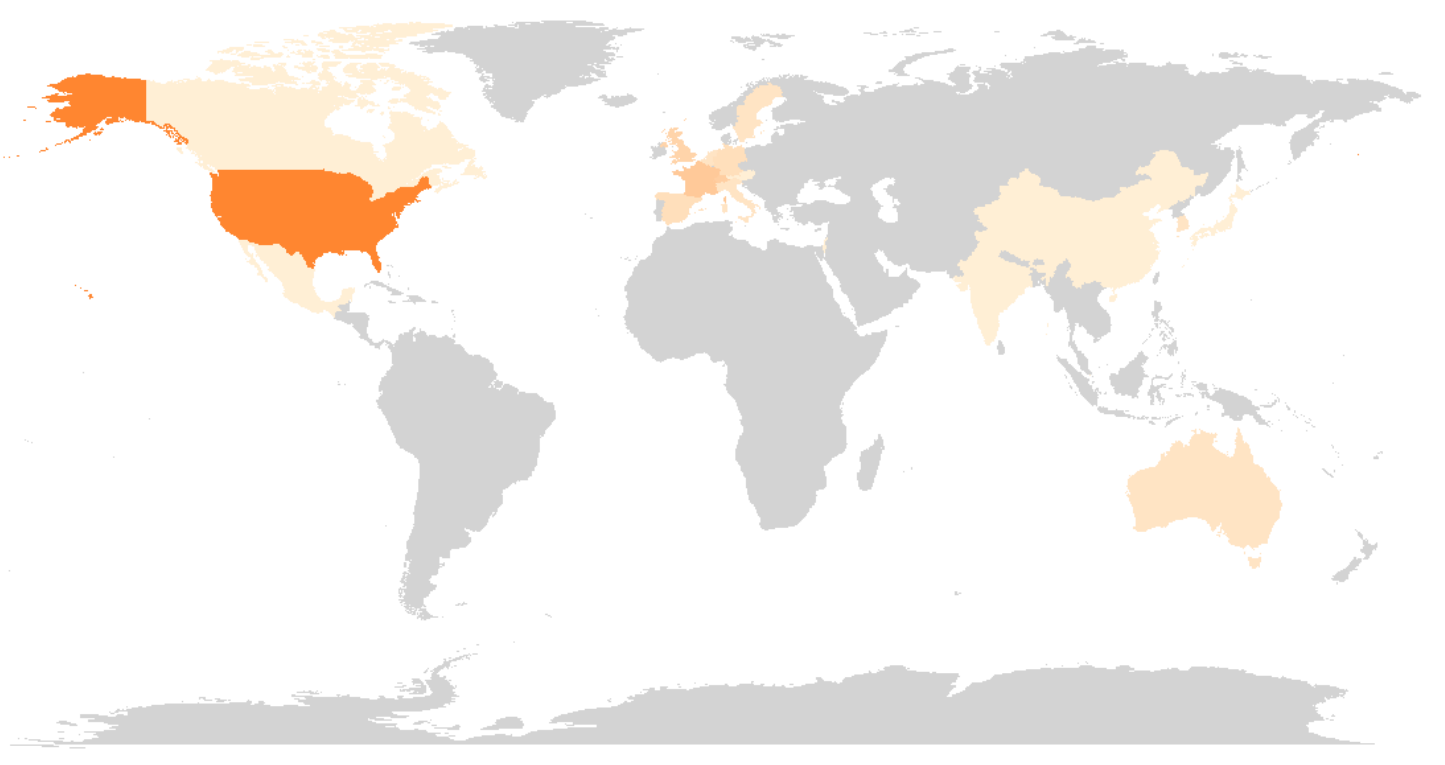

Figure 2: Number of ESG firms by country on map

Figures 1 and 2 show that there is strong concentration of ESG firms in Europe (notably France, UK and Switzerland) and North America (notably the US). On the one hand, this can be explained by the fact that these two regions account for the greatest share of funds that are managed to responsible investment criteria ( $46 \%$ of the global total in Europe and $39 \%$ in the US according to GSIA 2018). On the other hand, the data might reflect a bias from the researchers (including this paper) for actors in the Global North. It might thus be worth to pay more attention to ESG actors in so far understudied regions. 


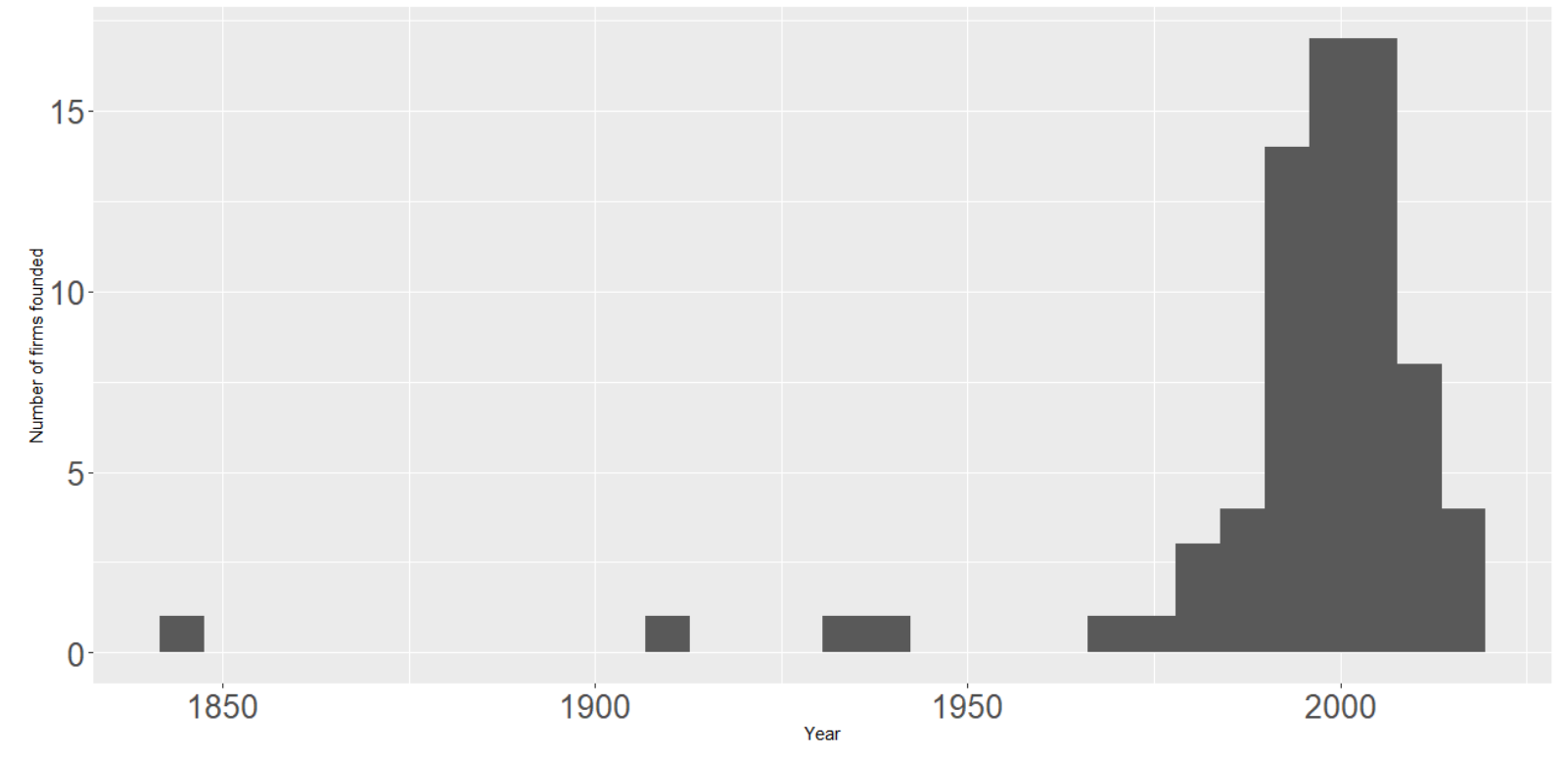

Figure 3: Establishment of firms

Establishment of firms: $1969-2018$

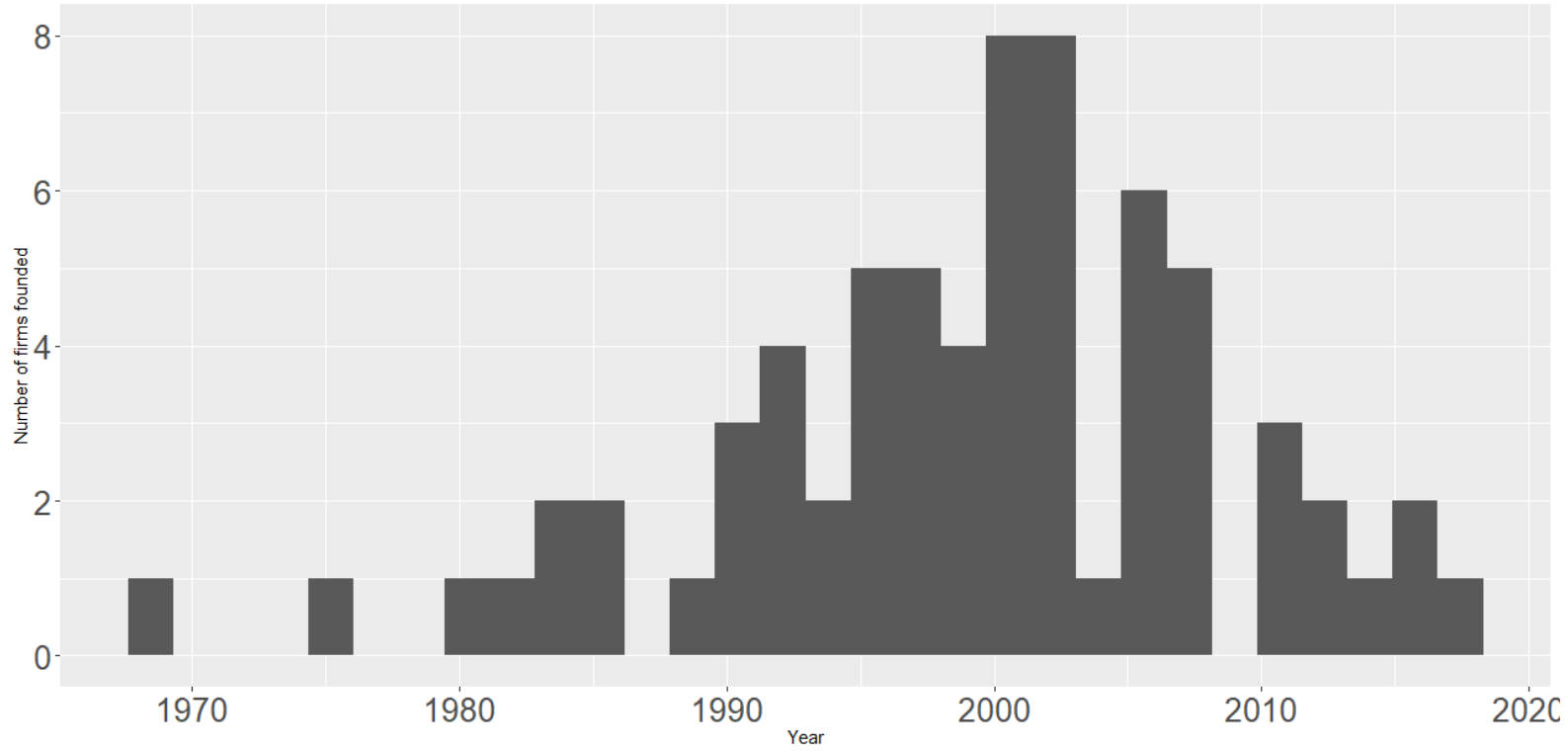

Figure 4: Establishment of firms: Reduced time frame

Figures 3 and 4 are histograms that show how many firms were established per year. Figure 3 notably goes further back in time as includes the incorporation of traditional financial service providers like Moody's (established 1846), which are part of the dataset by virtue of their acquisition activities. This notwithstanding, in both figures an increased activity can be detected in the 1990s and early 2000s. This observation is consistent with accounts on the history of CSR and ESG investing that highlight the relevance of the corporate scandals of the 1990s (e.g. Enron, Bhopal, Exxon Valdez) which gave further momentum to the practices of sustainable investing that had already risen to prominence against the 
background of the divestment campaigns of the 1980s that targeted the Vietnam war and the South African apartheid regime (Sparkes 2002).

\section{ESG firms: Mergers and Acquistions 2000-2019}

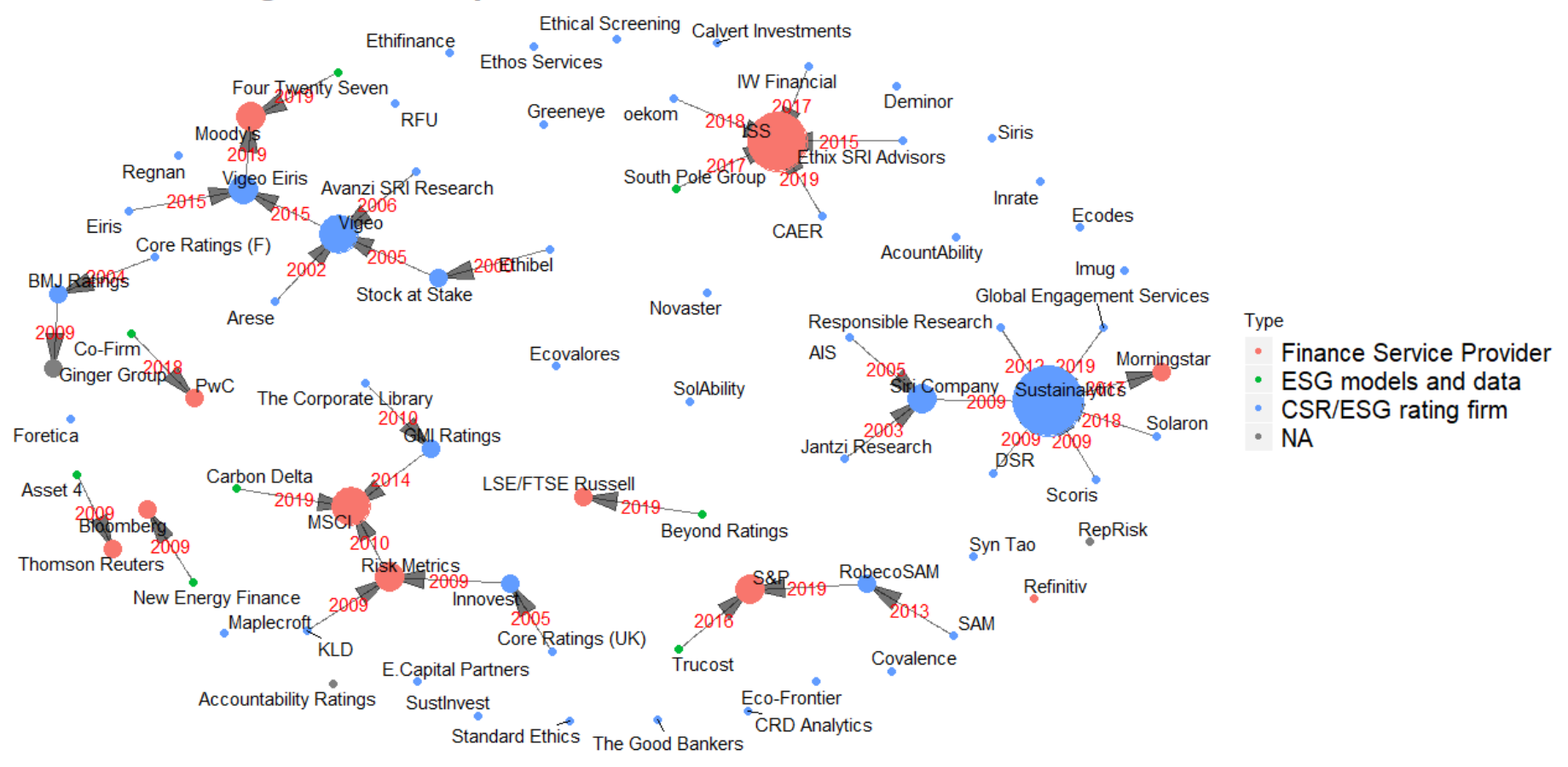

Figure 5: Network of Mergers and Acquisitions. Nodes scaled by incoming links (i.e. in-degree). Colours according to type. ESG firm names are in black. Years of mergers and acquisitions in red.

Figure 5 displays the relations among the 77 firms in terms of mergers and acquisitions. 29 firms are do not have any relations, i.e. they are isolates. Consequently, the remaining 48 firms have either merged with another ESG actor or have been bought. The largest component in figure 5 is located towards the right and features Sustainalytics in its center. Sustainalytics had brought together eight ESG firms before it was partly bought by the financial service provider Morningstar in 2017 (see also figure 6). The second largest component is on the upper left side and depicts the trajectory of Vigeo Eiris, which merged a leading UK and French ESG rating provider before being acquired by the credit rating agency Moody's in 2019.

These two episodes already hint to a larger phenomenon that is illustrated in figure 5 by the node colour. Whereas traditional ESG rating providers that had often catered to religious and ethical investors are represented by blue nodes, the red nodes indicate more mainstream financial data providers. Finally, the green nodes depict ESG firms that do not provide traditional ESG ratings that often feature qualitative analysis. Instead, these actors that mobilize larger datasets and modelling 
techniques (some of them also being referred to as FinTechs). From observing figure 5 it becomes clear that while there has been considerable consolidation within the space of traditional ESG rating firms (blue nodes), at the end of each of the bigger clusters there is a red node, i.e. a mainstream data firm buying up the "winning" ESG provider. This separation of two types of ESG mergers is also made by Avestisyan and Hockerts (2017: 327). In addition, the green, tech-savy data providers have also all been acquired by mainstream financial services firms

Figure 6 zooms in on this development by isolating the part of figure 5 that relates to the consolidation of ESG data in the hand of established firms and displaying it in a timeline. Figure 7, finally, summarizes the number of mergers and acquisitions per year in a histogram.

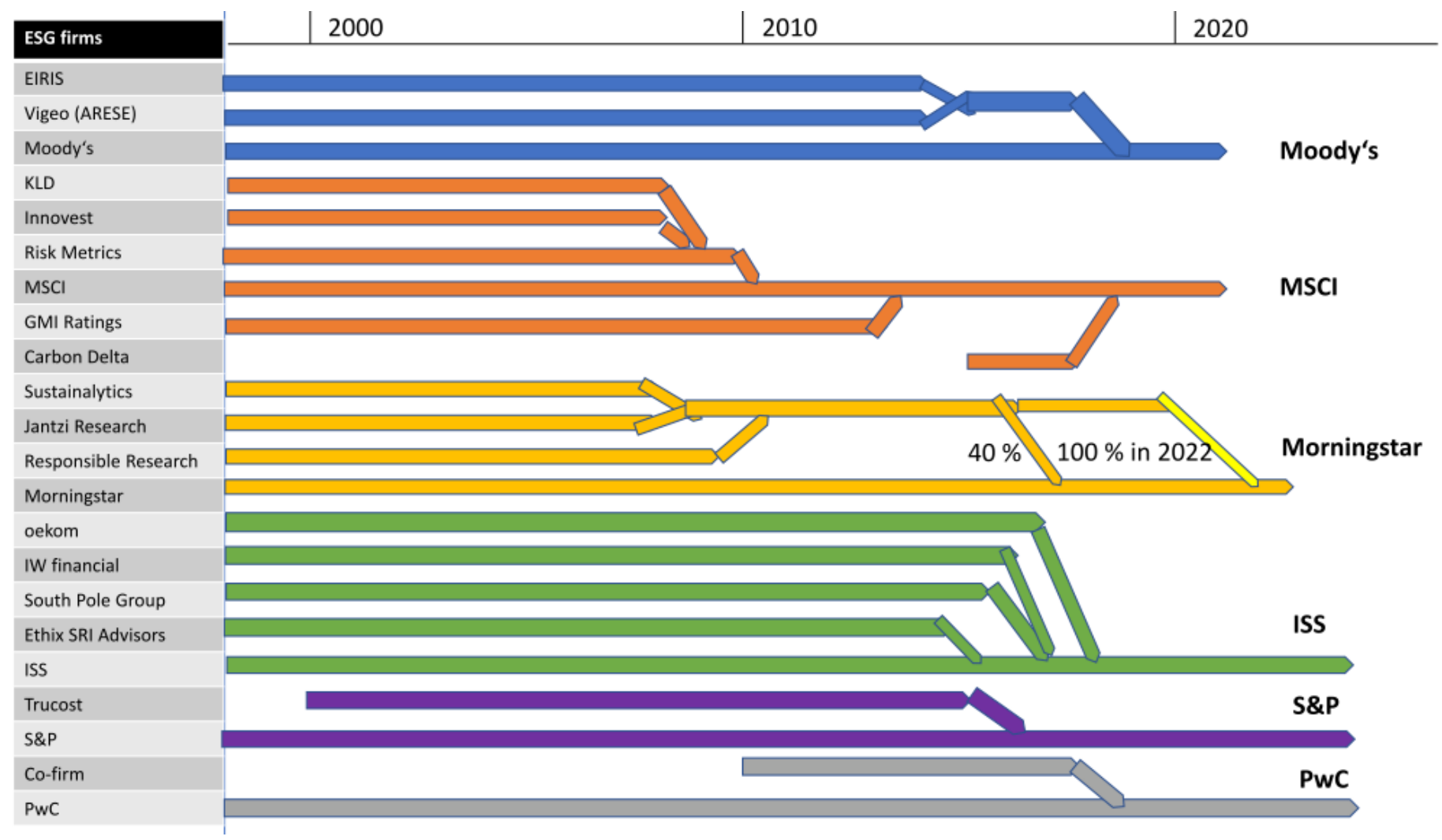

Figure 6: Timeline of consolidation in the hand of established financial service providers. 


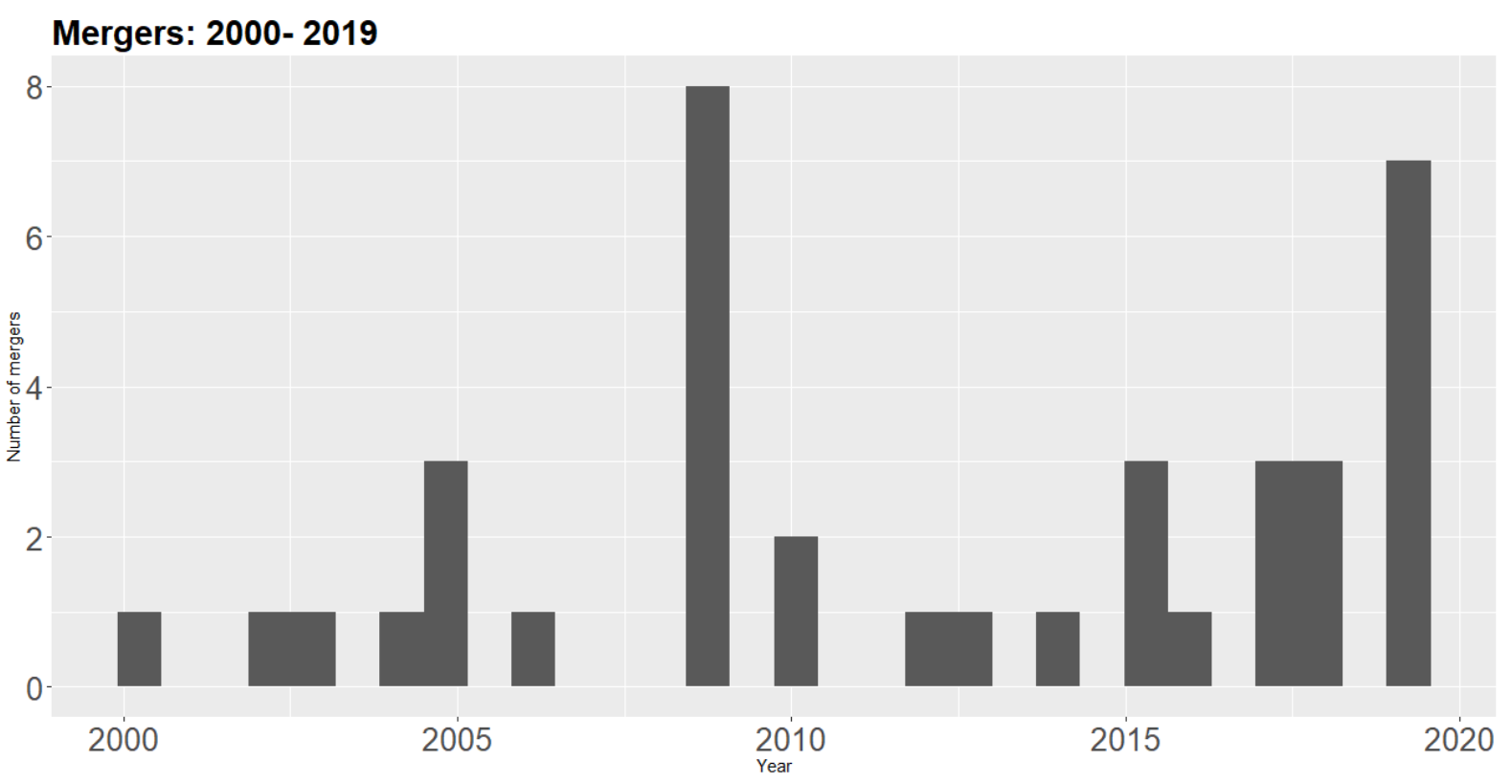

Figure 7: Mergers and acquisitions per year

Figure 7 records the highest activities for the years 2008 and 2019. Whereas the consolidation in 2008 could be related to mergers of ailing firms during the financial crisis, the more recent peak could reflect the shadow of regulation that induced the financial service providers to expand their ESG departments (cf. Olmedo et al. 2010: 445). An additional explanation that has been offered in the literature is related to the demand side and stipulates that as investors require an ever more inclusive coverage of data on (at best) all available securities, (especially regional) ESG firms are driver towards consolidation (Avetisyan and Hockerts 2017: 325). As the last five years saw an increasing interest of large diversified investors like pension funds and asset managers in sustainable finance, the latest peak in the data could possibly also be related to this driver.

\section{Conclusion}

This paper mapped the actors that perform the work of translating sustainability to finance by sourcing, processing and evaluating ESG criteria. It provides a new, aggregated dataset of ESG firms and the mergers and acquisitions among them. It showed that while there remain many independent ESG firms, established providers of financial services have acquired a fair portion of already consolidated firms.

As opposed to some of the detailed studies on ESG methodologies (e.g. Olmedo et al. 2010), this paper can only make implicit assumptions about the meaning of the consolidation. Nonetheless, the involvement of established data providers could indicate that the initial departure from the norms and categories of the financial industry that some ESG firms displayed might be reversed (cf. Avetisyan and Hockerts 2017: 328). 


\section{References}

Adelphi (2020). European Sustainable Finance Survey 2020.

Avetisyan, E., \& Ferrary, M. (2013). Dynamics of Stakeholders' Implications in the Institutionalization of the CSR Field in France and in the United States. Journal of Business Ethics, 115(1), 115-133. https://doi.org/10.1007/s10551-012-1386-3

Avetisyan, E., \& Hockerts, K. (2017). The Consolidation of the ESG Rating Industry as an Enactment of Institutional Retrogression: Consolidation of the ESG Rating Industry. Business Strategy and the Environment, 26(3), 316-330. https://doi.org/10.1002/bse.1919

Bernards, N., \& Campbell-Verduyn, M. (2019). Understanding technological change in global finance through infrastructures. Review of International Political Economy, 26(5), 773-789.

https://doi.org/10.1080/09692290.2019.1625420

Braun, B., (2018). Central banking and the infrastructural power of finance: the case of ECB support for repo and securitization.

markets. Socio-economic review, 1-24.

Brown-Flynn (2018). The ESG Ecosystem.

Chatterji, A. K., Durand, R., Levine, D. I., \& Touboul, S. (2016). Do ratings of firms converge?

Implications for managers, investors and strategy researchers. Strategic Management Journal, 37(8), 1597-1614.

Christophers, Brett. 2017. 'Climate Change and Financial Instability: Risk Disclosure and the Problematics of Neoliberal Governance'. Annals of the American Association of Geographers 107(5): 1108-27.

Eccles, R. G., \& Stroehle, J. C. (2018). Exploring social origins in the construction of ESG measures. Available at SSRN 3212685.

Escrig-Olmedo, E., Fernández-Izquierdo, M., Ferrero-Ferrero, I., Rivera-Lirio, J., \& Muñoz-Torres, M. (2019). Rating the Raters: Evaluating how ESG Rating Agencies Integrate Sustainability Principles. Sustainability, 11(3), 915. https://doi.org/10.3390/su11030915

Global Sustainable Investment Alliance, GSIA (2018). Global Sustainable Investment Review 2018. IMF (2019). Global Financial Stability Report: Lower for Longer. October 2019.

Olmedo, E. E., Torres, M. J. M., \& Izquierdo, M. A. F. (2010). Socially responsible investing: Sustainability indices, ESG rating and information provider agencies. International Journal of Sustainable Economy, 2(4), 442. https://doi.org/10.1504/IJSE.2010.035490

Naumann, B. and Temple West, P. (2020) BofA Chief Leads new Effort to Tame Unruly ESG Metrics. Available from: https://www.ft.com/content/876f143a-36de-11ea-a6d3-9a26f8c3cba4 [Accessed 11May 2020].

Novethic (2013). Overview of ESG Rating Agencies

Petry, J., Fichtner, J., \& Heemskerk, E. (2019). Steering capital: The growing private authority of index providers in the age of passive asset management. Review of International Political Economy, 0(0), 1-25. https://doi.org/10.1080/09692290.2019.1699147 
Principles for Responsible Investment, PRI. (2020). TESTING THE TAXONOMY INSIGHTS FROM THE PRI TAXONOMY PRACTITIONERS GROUP.

Sparkes, R. (2002). Socially Responsible Investment: A Global Revolution. Chicester: JohnWiley SustainAbility (2010). Rate the Raters Phase Two: Taking Inventory of the Ratings Universe- October 2010

Sustainability (2020). -ratetheraters2020-report.pdf. (n.d.).

The Economist (2019) "Poor scores: Climate change has made ESG a force in investing" Economist, December 7th, 2019. https://www.economist.com/finance-and-economics/2019/12/07/climatechange-has-made-esg-a-force-in-investing. Accessed January 23rd, 2020.

Thistlethwaite, J. (2015). 'Private Governance and Sustainable Finance'. Journal of Sustainable Finance \& Investment 4(1): 61-75.

Thompson, J. (2019). "ESG rating agencies fulfil the need for knowhow", Financial Times, May 12th, 2019, https://www.ft.com/content/2cd37df8-a973-3f94-b498-09ee1a6ba53b. Accessed June 13th, 2019. 